\title{
ASTIN DONATES MAJOR ACTUARIAL BOOKS TO 120 UNIVERSITIES IN EMERGING COUNTRIES
}

Article 2 of the ASTIN rules state that ASTIN has as its objective the promotion of actuarial research, particularly in non-life insurance. To this end it organises the ASTIN Colloquia and publishes the ASTIN Bulletin. In addition to these two basic activities it may engage in other activities serving to advance the above objective.

During its September meeting in Copenhagen, the ASTIN Committee unanimously approved a proposal to donate 18 major actuarial books to 120 universities and actuarial associations in emerging countries.

The selection process took place as follows: in September 1995, in Brussels, the Committee created a task force, with the assignment to find ways to spend part of ASTIN's assets for the benefit of actuarial science in emerging countries. The task force wrote to the entire ASTIN Committee, the Editorial Board of the ASTIN Bulletin, and other respected ASTIN members (45 members in total), and asked them to recommend fifteen books. The selections were quite convergent, and 18 books clearly emerged as the best actuarial books recently published. The following table lists the selected books, by decreasing order of votes.

1. Daykin, Pentikainen, Pesonen.

"Practical Risk Theory for Actuaries"

2. Gerber

"An Introduction to Mathematical Risk Theory"

3. Bühlmann

"Mathematical Models in Risk Theory"

4. Lemaire

"Automobile Insurance: Actuarial models"

5. Bowers, Gerber, Jones, Hickman, Nesbitt

"Actuarial Mathematics"

6. Panjer and Willmot

"Insurance Risk Models"

7. Hogg and Klugman

"Loss Distributions"

8. Gerber

"Life Insurance Mathematics"

9. Lemaire

"Bonus-malus systems in Automobile Insurance"

10. Casualty Actuarial Society

"Foundations of Casualty Actuarial Science"

11. Institute of Actuaries

"Claims Reserving Manual" 
12. Straub

"Non-life Insurance Mathematics"

13. Taylor

"Claims Reserving in Non-life Insurance"

14. Van Eeghen

"Rate-Making"

15. Hossack, Pollard, Zehnwirth

"Introductory Statistics with Applications in General Insurance"

16. Van Eeghen

"Loss Reserving Methods"

17. Hart, Buchanan, Howe

"Actuarial Practice of General Insurance"

18. Kastelijn

"Solvency"

The authors and publishers of these books were contacted and responded enthusiastically to our project. All authors agreed to give up their royalties. Publishers provided discounts as high as $75 \%$. The books ranked 2, 3, 4, 14, 16, and 18 , that were out of print, are going to be specially reprinted, as an unexpected byproduct of our action.

The task force is in the process of putting together a list of recipient universities and national actuarial associations. While the list is not yet complete, recipients have already been identified in Albania, Belarus, Bulgaria, China, Croatia, the Czech Republic, Estonia, Egypt, Hungary, Georgia, Ghana, India, Jamaica, Korea, Latvia, Lithuania, Malaysia, Mexico, Poland, Romania, Russia, Slovakia, Slovenia, South Africa, Taiwan, Thailand, Turkey, the Ukraine, and Vietnam. It is expected that the books will be forwarded early in 1997.

The ASTIN Committee wishes to express its most sincere thanks to all members who contributed to this exciting project, with special thanks to Chris Daykin.

JEAN LEMAIRE 